PRIMARY TEACHERS, INSPECTION AND THE SILENCING OF THE ETHIC OF CARE 
This page intentionally left blank 


\section{PRIMARY TEACHERS, INSPECTION AND THE SILENCING OF THE ETHIC OF CARE}

BY

\section{JAMES REID}

University of Huddersfield, UK

\section{emerald PUBLISHING}

United Kingdom - North America - Japan - India - Malaysia - China 
Emerald Publishing Limited

Howard House, Wagon Lane, Bingley BD16 1WA, UK

First edition 2018

Copyright (C) 2018 James Reid. Published under exclusive licence by Emerald Publishing Limited.

\section{Reprints and permissions service}

Contact: permissions@emeraldinsight.com

No part of this book may be reproduced, stored in a retrieval system, transmitted in any form or by any means electronic, mechanical, photocopying, recording or otherwise without either the prior written permission of the publisher or a licence permitting restricted copying issued in the UK by The Copyright Licensing Agency and in the USA by The Copyright Clearance Center. Any opinions expressed in the chapters are those of the authors. Whilst Emerald makes every effort to ensure the quality and accuracy of its content, Emerald makes no representation implied or otherwise, as to the chapters' suitability and application and disclaims any warranties, express or implied, to their use.

\section{British Library Cataloguing in Publication Data}

A catalogue record for this book is available from the British Library

ISBN: 978-1-78756-892-1 (Print)

ISBN: 978-1-78756-891-4 (Online)

ISBN: 978-1-78756-893-8 (Epub)

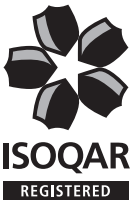

ISOQAR certified

Management System,

awarded to Emerald

for adherence to

Environmental

standard

ISO 14001:2004. 


\section{For Carol}

Thank you to the teachers of Crosstown Primary School who welcomed me and gave so generously of their time and experience. 
This page intentionally left blank 


\section{Contents}

List of Abbreviations ix

About the Author $x i$

Chapter 1 Developing Understanding of Teachers' Everyday Work During a Period of Inspection 1

Chapter 2 The Story Being Told 25

Chapter 3 Care Is Political: Situating the 'Ethic of Care' in a Conceptual Framework

Chapter 4 Politics First: Ideological Abstraction, Assessing Pupils' Progress and Blame

Chapter 5 Personal and Professional Moral Boundaries, Asymmetry and Categorisation

Chapter 6 Silencing Care: Achieving Fidelity to

Regulatory Demands

Chapter 7 Teachers' Experience and Understanding of Care

Index 
This page intentionally left blank 


\section{List of Abbreviations}

\begin{tabular}{ll} 
APP & Assessing Pupils' Progress: A Teacher's Handbook \\
CACE & Central Advisory Council for Education \\
CAF & Common Assessment Framework \\
CWDC & Children's Workforce Development Council \\
DCSF & Department for Children Schools and Families \\
DES & Department for Education and Science \\
DfE & Department for Education \\
DfEE & Department for Education and Employment \\
DfES & Department for Education and Skills \\
DH & Department of Health \\
ECM & Every Child Matters \\
ERA & Education Reform Act 1988 \\
HLTA & Higher Level Teaching Assistant \\
HMI & Her Majesty's Inspectorate of Education \\
ICT & Information and Communication Technology \\
IE & Institutional Ethnography \\
ILEA & Inner London Education Authority \\
LEA & Local Education Authority \\
NOVAC & Notification of Visits and Contact Form \\
NQT & Newly Qualified Teacher \\
NUT & National Union of Teachers \\
Ofsted & Office for Standards in Education, Children's Services and Skills \\
PGCE & Post Graduate Certificate in Education \\
QCA & Qualifications and Curriculum Authority \\
SEAL & Social and Emotional Aspects of Learning guidance \\
SIP & School Improvement Partner \\
SLT & Senior Leadership Team \\
TA & Teachistant \\
UNCRC & Unitens Convention on the Rights of the Child \\
\hline
\end{tabular}


This page intentionally left blank 


\section{About the Author}

Following a career in child and family social work and service development, Jim took up a post as a Lecturer in Social Work at Teesside University where his role included collaboration with UNICEF in central Asia. He moved to Huddersfield in 2008 to teach on childhood studies programmes at undergraduate and postgraduate levels. His $\mathrm{PhD}$ on primary teachers' experiences and understanding of care is a critical interpretation of mediating power in directing teachers' work. He has published extensively on child protection and safeguarding, the theoretical and practical underpinnings of education research and the challenges of the employability agenda. He has recently begun research into the application of the Finnish 'baby box' in Britain, with a particular interest in materiality and relational aspects of the box. 
This page intentionally left blank 
Chapter 1

\section{Developing Understanding of Teachers' Everyday Work During a Period of Inspection}

\subsection{Kathryn's Poem: A Teacher's Experience of Teaching in the Panopticon}

I wasn't here at the beginning of this

I am an oldie

I was 22 when I got my first job

I think the responsibility, a lot more responsibility

I liked to think of myself as being innovative and creative

I did do lots of different things

I think it has tweaked now

I had to sort of throw myself into that

I am pretty good at it now

I think some aspects that are better

I think maybe the children are getting a better education

I certainly teach them more specifics

I would never have been teaching

I was never taught myself

I think we are teaching them 'how'

I think it is healthy to learn a lot of methods

I do question sometimes

I think sometimes that can be counterproductive

I think some sides of it are onerous

I think the planning side is far too onerous

I don't quite see the point

I do it twice 
I could do without

I am waiting for the year when my life becomes more organised

I think there are several factors

I am a factor

I am someone who wants to do my job well

I will dot 'I's and cross, cross 't's

I want to be seen

I am not handing in something substandard

I have always been someone of that nature

I need someone to say

I haven't been asked to do that for a long time

I was not in the practice of planning

I would only plan for maybe two or three days

I have to teach

I deviate from doing

I might plan it

I won't do it

I am redoing something

I don't know. It's accountability

I would say on the whole

I have certainly been happier here than I was at my past school

I am still working hard

I was working hard before

I am doing all this bloody work

I think that can be aggravating

I fell victim to this a couple of years ago

I inherited a class

I was told these are the levels

I wish I had been a stronger person

I think it has been the practice in this school

I adopted people who had just pushed up

I have had that happen to me and it's horrible

I don't know directly what they think of me

I hope they think I do okay

I held my end in the Ofsted

I got good feedback

I know I am very certain 
I feel I have done my job

I have been observed, I don't know how many times now

I didn't do that very well

I'll do it better next time

I know through doing

I've never known the like!

I have never known the like!

I have never known it

I have never known it before

I just find it fascinating

I know when I started

I thought, why?

I just don't know

I am, I am!

I still want to do my best

I felt I had to somehow justify

I was worthwhile to have

I was going to come in and be valued

I have done what I would do

I would like to feel I do my job well

I would like to feel I can hold my head up

I have done the best that I can

I got in a bit of a flap panicking the first term

I was asked to give reading assessments in October

I am sorry

I have them four afternoons a week

I am doing the best I can

I don't teach them literacy

I don't teach

I was offered the permanent post

I have come through; they can put a tick next to my name

I am not someone who is causing alarm

\subsection{Introduction}

Kathryn's poem is offered without explanation or context. Having read her poem, I invite you to consider what it reveals about Kathryn's experience in Crosstown School during a period of inspection? What is her understanding of herself as a teacher, her everyday work, her relationships within the school, how 
her work is mediated and how external relations of power shape her as a teacher and a woman?

This is the story of Crosstown Primary School, a school in the north of England, during a period of inspection by the Office for Standards in Education, Children's Services and Skills (Ofsted) in which the school was judged as 'performing less well than it might in all the circumstances reasonably be expected to perform' and, therefore, requiring improvement. It draws on the findings of an institutional ethnography (IE) (Smith, 2005), when I had privileged access to the teachers and school throughout the inspection period (Reid, 2016a). IE explicates how people in their everyday experiences take up various texts that mediate their work. Texts may be paper based; for example, policy documents or guidance, or artefacts, tools, material objects and talk. In explicating the texts that mediate teachers' work, IE reveals relations of ruling, or relations of power, through which the everyday work of people in a local site is directed by those removed from the intimate, social relations of that site.

The institutional ethnographer does not enter the local site with any a priori ideas of concepts, issues or problems. The 'problematic' for investigation is revealed from the everyday work and talk of the people within that local site (Smith, 2005). Consequently, the teachers' experiences and understanding of 'care' became a problem for investigation since, within minutes of my first time in the school, I was told, 'we are a very caring school'. The comment by Brenda, the head teacher, was deliberate and made to convey a message about a disjuncture in experience of which I was not yet aware. Subsequently, care was a consistent aspect of the teachers' talk and was a significant feature of the ethos of the school.

A concern for care is consistent within studies of teachers' work over time; for example, the seminal Plowden Report (Central Advisory Council for Education (CACE), 1967) and Jenny Nias's (1989) Primary Teachers Talking, both of which were written at a time of particular ideological struggle, raised teachers' concerns about the purposes of teaching and the developing instrumental requirements of education. The former implicating care; the latter increased governmentality of teachers' work and was indicative of how politics pervades teachers' everyday work (Tronto, 1993). While the concept of care was foregrounded in Crosstown, it was vocalised from a perception of being 'other', that is, the teachers' understanding themselves to be other than the desired professional required by externally imposed frames of accountability.

The teachers were concerned about being 'different', 'a risk' and 'at risk' on a number of different levels. An obvious interpretation is a risk through poor teaching and professional performance to the children's education and outcomes. Assessed from the standpoint of the external observer, the Ofsted inspector, the teachers were graded, 'outstanding', 'good', 'requires improvement' or 'inadequate' on the quality of their practice and their ability to improve pupil's outcomes over each term in an academic year. There were individual outcomes from 'outstanding' to 'requires improvement' and, therefore, differentiation within the staff team. It could, of course, be argued that this is a typical outcome given the range of knowledge, skills and experience in any staff group. However, 
the issue for the teachers at Crosstown was both personal and professional. It is easy to conclude that a teacher who receives a 'requires improvement' grading is professionally a risk to the overall assessment of the quality of provision in the school and also risky to her pupils and colleagues. On a personal level, she is also aware of the difference between her and her colleagues with a higher grading and comparison and, perhaps, envy is inevitable. This is also the case for the teacher who receives 'outstanding' but who is unwilling to celebrate her success, since to do so would risk further the morale of colleagues. The embodiment of the inspection process also moves beyond the boundaries of the school to other areas of the teacher's life and, for example, can also develop challenges to those relationships. Consequently, their aim, also vocalised by Brenda, was to 'do whatever is necessary to get out of this'. This aim was both professional and personal; the objective was to enhance the reputation of the school as a good and caring school and to reflect the teachers' concern for each other and others.

Care, therefore, is understood and experienced in a social milieu. It is not fixed and, importantly, I do not posit care simply as a practice or an emotional exchange between one person to another. It not only involves relationships but also moves beyond this to the political, to 'relations of ruling' (Smith, 2005). This involves how teachers' practices of care are coordinated and mediated through institutional relations. In this context, 'institutional' relations of ruling involve texts including the policies, guidance and wider regulatory texts that are taken up by teachers as an aspect of their everyday work within a performative agenda for schools. Consequently, in positing political and social power as an aspect of teachers' everyday experiences of care I foreground Joan Tronto's (1993) argument for a 'political ethic of care' as an appropriate theoretical and epistemological model; and as an alternative to approaches that individualise teachers' caring practices as only belonging in the intimate, proximal domains of caregiving and care receiving.

In developing this argument, the 'ethic of care' is understood in relation to the three branches of moral philosophy - metaethics, normative ethics and applied ethics. Typically, metaethics' concern is moral principles and questions of where our moral judgements come from; for example, is it a matter of the will of a powerful deity or individual reason or ego? Normative ethics focus on moral standards and notions of what is right or wrong based on duties or the consequences of actions. Applied ethics attempt to resolve the questions of the previous two branches for specific contexts and issues; for example, the standards, duties and consequences of care. Although these may be presented as three distinct branches of moral philosophy there is inevitably crossover in their boundaries, for example, care may be presented as an applied ethical concern since it involves a controversial (sometimes) aspect of human interaction and work. However, this also depends on understanding more general normative notions of choice, dependency, rights and responsibilities which help to frame the moral boundaries of care work. This, in turn, involves metaethical questions such as where do rights come from? Whilst it is important to understand the conceptual framework for care in light of these three branches of moral philosophy, its structure is also drawn from a particular theoretical and epistemological 
standpoint. I argue, therefore, at the metaethical level, care is a matter of political and social interaction rather than individual reason; normative ethics involve considerations of power and responsibility rather than duty or consequence; and finally, the applied ethic of care is achieved through a political theory. In this regard, the political ethic of care brings together the three orienting approaches to moral philosophy to form a coherent conceptual framework for understanding teachers' experiences of care during a period of 'notice to improve'.

\subsection{Beginnings}

During an informal lunchtime, when I was exploring with the teachers their experience of working with parents, their talk turned to other concerns, in particular, their thoughts and feelings on having recently been judged by Ofsted as a school requiring improvement. They talked of 'stress', 'action plans', 'school improvement partners' (SIPs) and needing to change their working practices so that they could shed the 'damaging' and 'critical' judgement and be recognised for the 'good school that we are'. I noted that the conversation was animated, if not agitated, and they were vocal of their feelings. They were 'frustrated', 'unhappy' and 'angry' about the inspection judgement, their treatment during the inspection process, and what they viewed as an 'unfair' outcome. In my notes, I wrote how 'all but one of the group looked to the senior teacher... as a sign of permission needed following the inspection outcome'. I questioned this as an indication of power at play, specifically involving those exerting power from the outside.

I followed the teachers' lead in the conversation and we discussed Ofsted requirements, their sense of being unfairly treated, the implications of having a 'notice to improve' and what they needed to do to achieve a better outcome during subsequent monitoring inspection, which would be within a year. I accessed the Ofsted report, a public document, which recommended that the school needed to take the following actions to improve:

- Increase the rate of pupils' progress and raise attainment in English, mathematics and science in Key Stage 2 by:

- improving the quality and consistency of all teaching to a good or better level to ensure pace and challenge for pupils in all lessons;

- checking that pupils have targets and always know how to achieve them.

- Further improve the quality of leadership and management by:

- ensuring that monitoring of teaching and learning focuses more consistently on pupils' learning;

- giving subject leaders more opportunities to check on their subjects so that they can make informed decisions about what needs doing to secure improvement;

- using information about pupils' performance more systematically to drive and secure improvement. 
The foregrounding of targets, monitoring and performance management and the teachers' collective desire to demonstrate 'improvement' brought to mind issues of performativity in teachers' work (Ball, 2003). Moreover, I began thinking about teachers as policy actors (Ball, Maguire, Braun, \& Hoskins, 2011) and 'chaos' (Dewar, 1998) in the enactment of law and regulatory requirements relating to children and their families. This arose in part because of my previous professional role as a social worker who had experienced Ofsted inspections, albeit not in an educational context. In particular, I was aware of their collective desire, voiced by the head teacher, to 'do whatever is necessary to get out of this', to get out of notice to improve. I was also conscious of the teachers' comments about how they managed their time differently indeed of how potentially time-poor they were. This was a persistent theme throughout my contact with them as the following comments from several of their diaries demonstrate:

- 'Finished work at 10:10 p.m. ... absolutely shattered'.

- 'Most of us there to 5:30 p.m. tonight. Even me who usually on Friday is off like shit off a shovel at 3:30 p.m.'

- 'Another night not until 6:15 p.m. this week ... after spending the past two weeks staying until 5:30 p.m. plus.'

This insight into the teachers' experience of inspection gave rise to a unique possibility of observing the teachers' experiences during an inspection period (indeed I was present during an inspection visit) and of developing an understanding of the organising power of the inspection process. Several questions began to shape the research:

- What are teachers' experiences of the inspection process and 'notice to improve'?

- How does an inspector's report of a particular school reflect wider national and global policy?

- What dilemmas do teachers identify when working within a performative framework?

Following discussions and consultation with the deputy head teacher and head teacher, as gatekeepers, and their subsequent consultation with their colleagues, I was given permission to enter the school, weekly on a Friday with additional days and block weeks where appropriate. Ad hoc contact continued with the school over five years. The focus of my research would be on the teachers' experiences of inspection and not on the pupils. Consequently, a role was negotiated for me to be in school as a volunteer with unhindered access across the school as long as there was no disruption to the children's learning. However, my intention initially was to undertake a critical policy analysis and I had not thought of, until my subsequent meeting with Brenda on my first day in the field, care as a problematic for investigation. 


\subsection{A Pen Picture of Crosstown Primary School}

Crosstown is a small maintained community primary school in a suburb of a large city in the north of England. There are approximately 196 pupils on a roll; the number fluctuating by small amounts as pupils move in or out of the area during the academic year, with a single intake each year. The pupils are aged between four and eleven through Reception class, Key Stage 1 (five to seven, rising eight) and Key Stage 2 (eight to eleven).

The majority of staff and pupils are of White British backgrounds with a small number from other ethnic backgrounds. The school catchment area includes a ward in the top 10 percentile for social deprivation nationally. Consequently, the school receives higher than average funding from the government to pay for free school meals and additional support. Twenty-five per cent of pupils receive free school meals. However, the number of pupils with special educational needs or a statement of special educational needs is just below the national average.

With the exception of the site manager all of the staff at Crosstown are women; consequently, all of the participants in the research are women. At the outset of the study, in addition to the head teacher, there were two full-time and two part-time (job-share) teachers in early years/Key Stage 1 and three full-time and two part-time (job-share) teachers in Key Stage 2. However, of the two job-share teachers in Key Stage 2, one was appointed to the role of deputy head teacher early in the study and effectively worked full-time. An additional part-time teacher worked across the school providing literacy support to pupils. All teachers agreed to participate in the study although this did not include the literacy support teacher in terms of interviews due to constraints on time and availability. An additional teacher was recruited during the study and she also agreed to take part. In total 12 teachers agreed to participate in the study.

Teaching assistants (TAs) are also employed across each year group to help the children and the teachers. Of the ten, two are higher level teaching assistants (HLTAs), that is, they have additional training and responsibilities across the school. These two also agreed to take part in the study, as did the TA who works predominantly in year 5 and year 6 , the classes where I was predominantly based.

\subsubsection{The Teachers}

Norma - started her teaching career as a playgroup assistant in her daughters' nursery. At that time, she undertook the required qualifications which enabled her to become a TA at a private school. Since she already possessed a degree, she undertook a Post Graduate Certificate in Education (PGCE) and has been teaching at Crosstown for six years since completing her PGCE. Norma was employed on a full-time contract at the time of the 2010 inspection, but decided to move to part-time hours thereafter. 
Julie - completed an undergraduate management degree before finishing her teaching qualification in the academic year 1999/2000. She joined the school soon after graduating initially in Key Stage 1 and over the next nine years worked with each year group in the key stage. During this time, she also had maternity leave on two occasions. Since 2010 Julie has been teaching in Key Stage 2, teaching a class which she original taught in the reception year and subsequently in year 2 .

Charlie - also graduated in 2000 with a Bachelor of Education qualification. She originally worked in Liverpool but changed jobs when her partner's job moved and there was a chance to live closer to her parents. She initially took a post as maternity cover before moving within the city to Crosstown as it offered a full-time permanent position. She taught in Key Stage 2 and both of her children have been born during her tenure at Crosstown. Charlie has since left the school and is now a head teacher in another local authority.

Lyn - did a biology degree before applying to do her teaching qualification, a PGCE, in Bristol. Her father and sister are also teachers. She taught in two schools, in years 3 and 4 and was about to move into year 6 when she took a post in Crosstown in Key Stage 1 with a science allowance. She then married and moved to another school in the city that offered a part-time job following the birth of her baby. After 10 years she did a job-share in the nursery and then Reception class before returning to Crosstown on a full-time basis, again in Key Stage 1.

Kathryn - did four years' teacher training straight from school, qualifying in 1985. She taught Maths at a secondary school for two years before changing to a junior school and then to an infant and junior school as a middle manager for four years. She stopped working following the birth of her child. Although still involved in her child's school as a treasurer she was out of teaching for 11 years before doing a return to teaching course. She initially worked as a supply teacher before taking a permanent position in Crosstown in Key Stage 2.

Sam - began her work in Crosstown as a parent helper in 1999 before taking a post as a lunchtime assistant. After a number of weeks, she took a TA post working in Key Stage 1 in the mornings and soon afterwards with Key Stage 2 in the afternoons. Throughout her time in the school, she has worked with all of the teachers but primarily in year 6 .

Heather - has always wanted to be a teacher and initially gained a nursery and child care qualification. She subsequently did a Bachelor of Education programme, qualifying in 2007. In the two years after qualification, she had a number of supply posts, including for maternity cover, which enabled her to complete her newly qualified teacher (NQT) year. When her husband lost his job, they relocated to the city where she initially got a job at Crosstown covering 
Julie's maternity leave. She left Crosstown, again taking supply posts, before returning to cover a long-term absence in Key Stage 1. She is now permanently employed at Crosstown.

Maggie - has been teaching for 18 years in 2012. She worked in another part of the county for eight years before taking a part-time post for the next seven years following the birth of her son. She was then made redundant and took on supply teaching roles. Her children attended Crosstown and she made a decision not to work there but worked as a supply teaching in the neighbouring schools for three years. When her oldest son left Crosstown she was offered a long-term post to cover absence in Key Stage 1 on a part-time basis. She continues to work part-time but permanently.

Brenda - is the head teacher at Crosstown. She qualified in 1979, working initially in a middle school where she specialised in art and children with special educational needs in the primary phase. Subsequently, she changed jobs six times, remaining focused on inner-city schools and children with special educational needs or difficult behaviour. She was promoted to the role of deputy head teacher and then decided to take up a role with the local authority as a literacy adviser. She soon realised she missed the everyday interaction with the children and applied for her current post at Crosstown in 2002/2003.

Anne - joined the school in her NQT year to cover another teacher in Key Stage 1 on long-term sickness absence. This period within the school was successful and she eventually gained a full-time permanent post when her colleague Norma moved to part-time hours. Anne was a member of the teaching team when the school moved out of 'notice to improve', achieving a 'good' rating in the 2013 inspection.

Nellie - started her career teaching Dutch to adults for seven or eight years but the closure of the business led her to work from home doing the translation. During this time, she had two children, becoming a parent governor at Crosstown. She volunteered at the school before being offered a TA position as a cover for sickness absence. She subsequently applied for and got a permanent part-time job in year 6 . Since 2001/2002 she has developed her role, undertaking courses to enable her to achieve her position as an HLTA.

Marie - wanted to develop the skills and her interests gained as she brought up her children, who attended Crosstown. Beginning as a volunteer, she was offered temporary employment in the mornings in a TA role. This became a temporary contract for a year, 16 years ago! Since then she has undertaken additional training, first in early years work and then as an HLTA. She has been doing this role since $2002 / 2003$. 
Jennie - had been qualified for five years having undertaken her teacher training as a mature student. She began her career working with disabled children including in a high school as a support worker. Her experience with children with learning difficulties led her to teaching. She undertook teaching practice at Crosstown during her training and specialised in Key Stage 2. On graduation, she took a job in the school, however, in Key Stage 1. She had a sense of being underprepared for this role. She was also absent for a number of periods due to ongoing health problems.

Simone - is the deputy head teacher at Crosstown. She decided to get into teaching after beginning a science degree. She lived and worked in another part of the country before moving to the city with her partner and children, following her partner's new job. She took on supply jobs, including at Crosstown which eventually led to her getting a part-time job in Key Stage 2. As her own children got older she took on more responsibilities at the school developing a leadership role and now works full-time both teaching and leading.

\subsection{Dissatisfaction and the Inspection Regime}

My contact with Crosstown School began in 2010 and I acknowledge that there have been changes to guidance for schools since my research. However, the political and ideological abstraction of the purpose of education and teaching have been consistent since the 1980s.

Nias's (1989) work is particularly interesting as a site of comparison and normative reflection of developments since the 1980s, indeed many of the teachers at Crosstown entered the profession during that decade. Nias develops a binary where 'satisfiers' (1989, pp. 85-102) are recognised as factors related to the doing of the job, as effective and intrinsic. Job 'dissatisfiers' are independent and related to the context in which work is organised including policy, bureaucracy and supervision. Nias, to her credit, recognises this as a crude binary since the doing of work, the experience of work, is affected by 'everything that goes on outside schools as well as within them' (p. 132). Nonetheless, she continues to argue that those things in which teachers find satisfaction are immanently relational and include affective rewards from children's company, a sense of occupational competence, an extension of personal qualities, the company of other teachers and feeling autonomous (pp. 86-102). She sees these as moral and caring. She notes that, over the 10 years of the teachers' experience in her study, these sources of job satisfaction did not change. Importantly, she frames teacher satisfaction as an aspect of achieving a sense of self and draws on symbolic interactionism in balancing a sensitive 'I' with a pragmatic 'me'. This is perhaps seen in Kathryn's poem.

Conversely, 'there was a substantial growth in the level of job dissatisfaction... between the mid-1970s and mid-1980s' (p. 132). Significantly, the growth in teacher dissatisfaction over a 10 -year period develops in a context of the political, social and economic changes which resonates with the current period. 
There is a consistent theme of the increasing constraints on teacher autonomy, and consequently with how they could choose to work with the whole child in relationship, and:

Falling relative salaries, increased class sizes, cuts in resources and neglect of buildings; and perceived encroachment into teachers' control over classroom practice, staffing, and curricular policies, by parents and by local and central government (pp. 132-133).

The encroachment into teachers' control has in large part been achieved through the development of an inspection regime and the subsequent setting up of Ofsted. School inspection is a statutory role under the Education Act (2005). The process of school inspection in England involves the appointment of a team of inspectors by Ofsted. The lead inspector phones the school the day before the inspection visit which typically takes place over two to three days, depending on the size of the school and the type of inspection. Every school is inspected at least every five years but may receive an inspection visit more frequently if there are concerns about quality. 'Outstanding' and 'good' schools receive short 'section 5' inspection visits from Ofsted in acknowledgement of their prior attainment against the required standards. Schools that are judged otherwise, as 'requiring improvement' or 'inadequate', will undergo a more in-depth 'section 8 ' inspection under the auspices of Her Majesty's Chief Inspector (HMCI). Decisions to undertake a section 8 visit are on the basis of a risk assessment by Ofsted based on a range of concerns including:

- Pupils' academic achievement over time, taking account of both attainment and progress;

- Pupils' attendance;

- The outcomes of any inspections, such as survey inspections, carried out by Ofsted since the last routine inspection;

- The views of parents (Ofsted, 2017, p. 6).

The School Inspection Handbook (Ofsted, 2017) details the duties and responsibilities of inspectors and inspectors are required to make a judgement of:

- overall effectiveness;

- effectiveness of leadership and management;

- quality of teaching, learning and assessment;

- personal development, behaviour and welfare

- outcomes for pupils (Ofsted, 2017, p. 33).

Inspectors gather data through a range of methods including; review of documentation, metrics and statistics (particularly of pupil attainment and progress), pupil and parental feedback, and observation of teaching practise. Both the school and individual teachers are graded in terms of effectiveness. While the 
categories for labelling schools following inspection have changed - there is no longer, for example, a category of 'satisfactory' - the legislation and outcomes by which teachers are measured have not significantly altered. The findings of the study remain relevant for as long as performativity is a key feature of the inspection process.

\subsection{Methodological Considerations}

The focus of the book is on the findings of my study into teachers' experiences and understanding of care during a period of 'notice to improve'. However, it is important to acknowledge the methodology and data gathering methods that were utilised. In seeking entry to Crosstown Primary School I was aware that the school had undergone an inspection and was judged as requiring improvement. The teachers talk of 'stress', 'action plans' and needing to change their working practices so that they could shed the 'damaging' and 'critical' judgement and be recognised for the 'good school that we are' was of significant ethical concern. My decision to utilise IE (Smith, 2005) as the methodology came, in particular, when Brenda said, 'we are a caring school', and when Julie, following my observation in her class, challenged me and asked, 'are you a spy from Ofsted?' This led me to be reflexive of my own standpoint, the precarious nature of teachers' everyday work under a regulatory gaze and the power of the researcher who questions and observes (for further discussion see Reid, 2017a, 2017b). Pausing to think about my standpoint and my authority in the social actuality of the research gave further cause to consider epistemic privilege and issues of belonging to a community of institutional knowers. My 'institutional capture' (Smith, 2005, pp. 155-156) in the requirements of IE and being faced with the teachers' concern that I was a spy, that I was the embodiment of institutional relations of ruling, was revelatory of relations of ruling beyond this exchange between Julie and me. The imposition of sociological positions or ideas on the participants' experience, or the development of a discussion that privileges the researcher's position or knowledge, raises questions of power in the context of the school and beyond.

Developing from the Marxist idea of historical materialism, institutional ethnographers seek to understand and reveal how people's everyday and every night experiences and doings are governed through ruling relations. Historical materialism, therefore, posits that people do not exist apart from predominant ideas, philosophies, laws, moral codes, etc., but that both subject and object are embedded in the actual doings of actual people (Allman, 2007, 2010). For Marx, consciousness is individual and the capitalist system is a manifestation of the historical social relations of the political economy (Smith, 2011). These social relations develop and change over time so that the attributes of consciousness at the rise of capitalism are different from people's consciousness today. People's consciousness is a matter of individual experience in their everyday and every night work and the object of inquiry. Consciousness of the object of inquiry arises out of the subjective experience of individuals and consciousness, 
therefore, involves the object and subject in internal relation. As individuals come together, consciousness develops a social and material relation, that is, the actual experience of individuals and groups generates ideas through the materiality of language. This acknowledges not only the internal relation between consciousness and material experience but also an internal relation between peoples' objectivity and subjectivity (Allman, 2007, p. 33). In this regard, the individual's consciousness involves thoughts and feelings and her consciousness of the capitalist system may be implicit rather than explicit and may be expressed only through a sense of alienation.

In this regard, the teachers' experiences of inspection could only be understood from their standpoint. To have undertaken a critical policy analysis would have been to develop an approach from the concept of inspection and all that involves (objectivity, governmentality, performativity, enactment and so on) and to impose these concepts on the teachers. However, working from their everyday experience of inspection also enabled recognition of their subjective selves and the significance of care as a focus for inquiry.

\subsubsection{Standpoint}

Drawing on Marx, feminist standpoint epistemology developed from the late 1970 s as a critical theory with a particular interest in the production of knowledge and gendered practices of power (Harding, 1987, 1991, 2004). Harstock (1987), for example, posited a division of labour in which women's understanding of society arises as a consequence of their material conditions. She argued that women's and men's work in the division of labour is different and, therefore, women's everyday and every night experience offers the possibility of new understanding through a feminist epistemology. Even if women and men did the same job, Harstock argued, women also worked outside the capitalist system since they were expected to undertake an additional role within the home, as carer, mother and domestic worker. In addition, childbirth and child rearing offer women a unique insight into historically contingent discursive practices of care that privilege men. This double consciousness thus enabled women to speak of the world from their standpoint and consequently develop a more comprehensive understanding that accounts for both insider and outsider experience of the capitalist system (Harding, 2004).

Haraway (1991) and Longino (1999) also argue of the importance of socially situated knowledge since women's everyday and every night experiences are unique, as are the specific standpoints arising from those experiences. Important is their acknowledgement of not one standpoint, but multiple standpoints from which it is possible to produce a more objective understanding, or 'strong objectivity', of reality (Harding, 1993). In this regard, Haraway and Longino are both critical of a universalist approach to women's experience in Harstock's work. For them, acknowledging multiple standpoints offers the opportunity for knowledge to be between standpoints.

Harding (1991) goes further in suggesting that some standpoints produce more objective truth claims than others since some women experience greater 
oppression than others, the experience of the most oppressed producing more truthful interpretations. The researcher should, therefore, be aware of those social situations that 'tend to generate the most objective knowledge claims' (Harding, 1991, p. 142). Furthermore, in attending to the diversity between standpoints the researcher comes to understand how each group understands their own experience and their 'place within the wider social thus developing distinctive insights about systems of social relations in general in which their oppression is a feature' (Harding, 2004, p. 9).

The basis of standpoint is that research should start in people's social realities and that we can learn more about the social world in attending to multiple standpoints and in particular, for Harding, those of the most oppressed. The 'elaborate specificity' (Haraway, 1991, p. 190) of a particular group's experience suggests knowledge is generated 'in particular places at particular times' (Longino, 1999, p. 333). So, IE begins with the actuality of the teachers' everyday experience and posits texts as a key starting place in exploring a problematic. How texts are taken up is an acknowledgement of the social coordination of the everyday and the teachers' bodily being. Experience is a point d'appui, or point of departure, for exploring and understanding how people's intimate world is connected beyond their immediate social environs to those of others living and working elsewhere. The teachers in Crosstown interpret their world from their particular standpoint and are, therefore, not the objects of the research; rather experience is the key to explicating the institutional processes that shape their lives (Bisaillon, 2012). This is also crucial in aligning IE with Tronto's (1993) political argument for an ethic of care. To care well requires that the researcher does not consign care to some sort of essentialist, parochial, or patriarchal role but recognises the political relations of dominative power, and that particular relations in a local site are diverse, extending beyond the local site. Care is not just a concept but an experience in which the teachers' ideological and subjective selves are entwined, which can be utilised to explicate difference in relations of ruling.

The conceptual framework of Tronto's process of care allied to IE enables consideration from a particular site of the attentiveness, responsibilities, competence and responsiveness to care that are inherent in the ruling relations that mediate teachers' work. A range of ethnographic methods were used in generating data, including interviews. The focus here is on use of a particular aspect of a narrative method, The Listening Guide (Mauthner \& Doucet, 1998), specifically 'I' poems. The guide may appear as an unlikely approach to data generation and analysis in utilising a relational ontology because of its origin in developmental psychology. However, in developing the guide, Mauthner and Doucet have moved away from a purely dispositional, individualistic focus to account for people's activities in relation. Up to four readings of the data are suggested which can be undertaken in any order, at any time. Reading one focuses on the overall story being told, reading two on the voice and standpoint of each participant (involving 'I' poems in generating and analysing data), reading three on people's relation with the other and reading four on wider relations. 
In this book I utilise 'I' poems as empirical data to be read and analysed to develop an understanding of the powerful forces that mediate teachers' work.

\subsection{Reading the Book}

\subsubsection{Reading for the Story Being Told}

This reading takes the form of a preliminary analysis and the details of the field, the inspection process and outcome are part of this overall story. The goal is to get a sense of the teachers' everyday experience and how texts mediate this experience. The politics of an individualised, neoliberal education system and an individualised concept of moral responsibility are an aspect of this experience. The counter-argument to individualism is that policies, such as those framing neoliberalism, are engaged and enacted through a relationship with and between people so that standpoint' and, therefore, voice, context, location and place have relevance. The differences in approach are both epistemological and political. This first reading helps to develop understanding of how needs and care are being set and by whom and also enables early consideration of the political and moral boundaries that work to maintain the power and privilege of the political elite.

\subsubsection{Reading for the Voice and Standpoint of the Teachers - 'I' Poems}

This involves a reading for "the voice of "I" and the purpose is to achieve the standpoint of each participant, to explore the experience of each. It is an attempt to hear the person and their experience by focusing on use of personal pronouns. 'I' poems select 'I' phrases and maintain them in the sequence of the text in the form of a poem to explore experience. 'I' poems introduce each chapter of the book so that the teachers are present throughout.

While I use the poems, and some other examples of the teachers' talk, to illustrate my thinking and arguments of particular concerns or concepts in each chapter, each poem is also plural. That is, the poems are complex and rich descriptions of the teachers' multiple consciousness (Smith, 2005); a revelation of their experience in the particular environment of the school and beyond, of being a teacher and a woman, a mother, a partner. In Chapter 2, I explicate further the process of analysis in undertaking readings of the poems; however, that work was otherwise done in the thesis which is the basis of this book (Reid, 2016a). Since the poems foreground the teachers' experiences throughout the book and I would suggest you read them more than once before reading further into each chapter. I acknowledge the poems are partial however when reading ask yourself; what's the story being told, what relationships are evident and to what purpose, and what are the institutional relations of ruling? These are discussed throughout the book.

It is important to acknowledge that the poems were shared with the teachers who were asked for feedback. Comments included: 'I'm so proud of myself, I'm proud of everything I have done' (Charlie) and 'It's like the first time anyone 
has ever listened to me!' (Julie). These are particularly validating of the method but the comments alone don't encapsulate the embodiment of the poems by the teachers. While some read their poems in silence others read their poems aloud, to themselves and others. I would recommend that you also read the poems aloud, to hear what is being said and to listen to your bodily response to it.

The focus of the book is on the empirical findings of the research and not the particularities of IE, although it is necessary to highlight this in discussion throughout. This is because IE, the political ethic of care and The Listening Guide are entwined epistemologically, methodologically and as a method of data generation and analysis.

\subsubsection{Reading Three - Reading for Textually Mediated Relationships}

This reading focuses on the networks of social relations in order to explicate socially mediated understandings of responsibility. There is a need to understand, reveal and track moral actors and concomitant texts, including those who exercise responsibility at a step, or steps, removed from frontline work and who exercise control from a position of power. In this reading, the discussion moves to explore institutional ruling relations beyond the local site. One aspect of this is to draw out from mediating texts what shape teachers' experiences.

'Institutional' does not signify an organisation but a framework for experience and research, focused on coordinating and linked work processes occurring across multiple sites (DeVault \& McCoy, 2006). Coordination occurs when texts are taken up and in doing so when texts are used by the powerful to shape constructions of care that ignore broader approaches and conceptualisations. Tronto (1993) argues that 'privileged irresponsibility' occurs when these broader approaches and conceptualisations are ignored and consequently the powerful and privileged distance themselves from others' wider experiences. In this regard, the privileged defend their position by developing a narrative of benefitting all through normative, idealised and gendered constructions.

\subsubsection{Reading Four - Placing People Within Cultural Contexts and Social Structures}

This reading develops further the focus on the networks of social relations in order to explicate socially mediated understandings of responsibility. Where reading three looks for those who exercise responsibility this reading further exposes political and social mediating forces in teachers' work, including the way the teachers account to each other for the relationships, processes and values that define their responsibilities and work. This involves consideration of the political, personal and professional moral boundaries that arise as they navigate the complex web of subjective and objective understanding. Indeed, for Tronto (1993), care receiving involves the teachers' experiences in caring and the struggle to develop trust and solidarity in caring with each other in a context of privileged irresponsibility. 


\subsection{The Chapters}

\subsubsection{Chapter 1: Developing Understanding of Teachers' Everyday Work During a Period of Inspection}

\subsubsection{Kathryn's Poem Reveals a Teacher's Experience of Teaching in the Panopticon}

This introduction to the book provides an overview of the participants, Crosstown School and briefly introduces the methodology. It also introduces 'I' poems and an opportunity to read and consider Kathryn's experience of her everyday work in a context of school inspection with a dissatisfactory outcome. Her consciousness (Allman, 2007) as a professional reveals something of the performative agenda for schools and the instrumental consequences for practice when required to meet the performative demands of Ofsted. There are also indications of the sensuous activity of social belonging, or not belonging, to groups. There is recognition of the need for validation as an aspect of the regulatory process and professional recognition and, in this context, she begins to explicate her consciousness and the sensuous activities of caregiving and care receiving. She cares for her pupils and her work:

I have done what I would do

I would like to feel I do my job well

I would like to feel I can hold my head up

I have done the best that I can

Kathryn recognises that her practices have changed, some for the good, but not all! There is a sense of the loss of creativity and the development of normative practices:

I have come through; they can put a tick next to my name

I am not someone who is causing alarm

Yet, while this is imbued with an understanding of her responsibility to the other her poem also highlights the embodiment of her work which gives rise to her needs as a care receiver. At the most basic level it is to care for her own selfesteem. The epistemology and methodology briefly outlined in this chapter enable explication and consideration of teachers' bifurcated consciousness (Smith, 2005) as caregivers and care receivers.

\subsubsection{Chapter 2: The Story Being Told}

\subsubsection{Norma's Poem Reveals Further the Story Being Told}

This chapter begins with Norma's poem as a further example of the story told through the poems by the teachers of Crosstown School. Consequently, it provides insight into both Norma's experiences as a teacher, including at the time 
of inspection, and of ' $\mathrm{I}$ ' poems as a method of data generation and analysis. Like Kathryn's poem, I recommend that you read the poem a number of times and identify the broad themes, arising from Norma's experience. The chapter subsequently reveals aspects of my reading of the poem, including the centrality of texts in mediating teachers' work, the identification of care as an important aspect of teachers' understanding of their everyday experiences, the power of politics in shaping teachers' work, historically and materially, and teachers' bifurcated consciousness (Smith, 2005) so that they are aware, simultaneously, of their work and everyday experience as teacher and woman/mother/partner/ friend.

This is significant since this consciousness is both of the objective (and objectified) self and the subjective self, entwined (Allman, 2007). The objectified self in regulatory context is a matter of political and ideological abstraction that leads to teachers being 'other'. This disjuncture between the objective and subjective self-arise from her experience of being both caregiver and care receiver. Teachers care about both the needs of inspectors (the performative nature of the job), their own needs and the needs of children. However, when the teachers' subjective consciousness is taken into account, there is a need for balance between caregiving - meeting the needs of others - and care receiving - having one's own needs met. A disjuncture arises, embodied through stress and anxiety, when there is no consensus on caregiving, including the purposes of education and its relations. Feelings of stress and anxiety are exacerbated since understanding and accounting for the teachers' standpoint, working from a position of shared understanding and consensus, is also necessary for good care receiving. Importantly, this speaks to a moral boundary (Tronto, 1993, 2010) and power relations in teachers' everyday experience since what is desired in education is regulated by the political elite through a 'politics first' approach.

\subsubsection{Chapter 3: Care Is Political: Situating the 'Ethic of Care' in a Conceptual Framework}

\subsubsection{Brenda's Poem Reveals that Teachers' Work and Their Experience of Care Is Political}

Since care has been revealed as the problem for investigation it is important to consider the concept of 'care' itself and how it is understood within a political ethic. A politics first approach is achieved through policy and guidance that achieve the particular demands of those in power, but this is only possible by underpinning this policy and guidance in a particular conceptual framework. This frame does not fully account for the teachers' consciousness of their everyday and every night lives. It is, therefore, important to acknowledge the 'centrality of otherness' (Tronto, 1993, p. 13) in the teachers' moral thinking in their everyday world. As such the concept of care is not a priori but it arises in the teachers' everyday work. Consequently, the focus of this chapter is on different theoretical and epistemological approaches that have informed understanding of 
women's and teachers' work and I argue for an approach based in people's doings; in their everyday experience.

A significant aspect of this chapter is, therefore, on how metaethics and normative ethics underpin how care is understood. Where care is understood within a masculinist ethical frame and where care work is foregrounded in feminised and essentialist, individualised practices, thoughts and feelings, then care is political. Developing from the discussion of ethics focus is given to different 'waves' in the development of feminist approaches to the ethic of care. This begins with Carol Gilligan's (1982) challenge to the work of Lawrence Kohlberg as masculinist, to Nodding's (1984/2003) seminal work on moral education involving maternal traits, to Tronto's (1993) political ethic of care. In turn, each has critiqued the former but all have added to our understanding of care. Discussion highlights, in particular, the difference in approach between Noddings and Tronto.

For Noddings, caring focuses on 'assumed' needs (Noddings, 1984/2003, 2012), that is, what it is assumed the pupils need in their education and which is delivered in relationship with the teacher. This is different to 'expressed' needs, in which the teacher listens to the pupils, attends to their needs and responds appropriately. Inherent in the latter is an acknowledgement of needs that extend beyond what the curriculum or external agents define as desirable; it is a matter of 'engrossment' between people in which caring is embodied. The essential difference is how the teacher listens, is attentive to the affective condition of the pupil and responds in reciprocation (Noddings, 2012).

Important to Noddings' approach is proximity between caregiver and care receiver, however, Tronto (1993) argues care involves not just caring practices but moral practices since power is a feature of teachers' everyday work. It is clear from the teachers' poems that care extends beyond the local site, beyond proximal relationships between people, to involve the political shaped through responsibilities and duties framed by an ideology which serves to maintain the requirements and expectations of the privileged (Tronto, 1993). Therefore, any understanding of care must also acknowledge wider political and historical ruling relations.

\subsubsection{Chapter 4: Politics First: Ideological Abstraction, Assessing Pupils' Progress and Blame}

\subsubsection{Marie's Poem Reveals the Ideological Abstraction of Teachers' Work}

Where Chapter 2 reveals 'the story being told' and Chapter 3 explicates the concept of care arising through the teachers' everyday experiences and doings, this chapter begins to focus on relationships and wider relations. It explicates further the 'politics first' approach to highlight the ideological and political abstraction within wider children and families' policy that mediates and directs teachers' work. A significant aspect of this is, what is in the texts that are taken up by the teachers and that consequently mediate their work? It is not within the scope of this book to explore every mediating text, there are simply too many (consider 
the 'chaos' posited by Dewar, 1998). The focus, therefore, is on 'boss' texts, or governing texts (Griffith \& Smith, 2014, p. 11) that play a significant role in teachers' work, specifically primary legislation and guidance. The teachers have no choice but to activate these texts as they foreground the teachers' duties and responsibilities in legislation and guidance.

Teachers are both caregivers and care receivers; however, this is not simply an aspect of a particular psychosocial state, or of proximal relations. It involves questions of attentiveness and responsibility, of emphasis of caregiving over care receiving, which implicates those who seek to direct teachers' work at a distance from its intimate relations. Responsibility implies a hierarchy in both power and relationships and the chapter subsequently reveals how people are positioned in relation to each other and through what understanding of responsibility (Walker, 1998). If hierarchical practices of responsibility are political practices (Sevenhuijsen, 1998), focusing on the teachers' attentiveness and responsibility to caregiving and care receiving works to explicate wider relations of ruling. An aspect of this is their attentiveness to what is in regulation, policy and guidance.

\subsubsection{Chapter 5: Personal and Professional Moral Boundaries, Asymmetry and Categorisation}

\subsubsection{Charlie's Poem Reveals Personal and Professional Moral Boundaries}

This chapter moves discussion from politics first moral boundaries to focus on personal and professional moral boundaries. Beginning with Charlie's poem the chapter also draws on examples of text (talk) from many of the teachers to explore their experiences as caregivers and care receivers. As such, the discussion develops further the theoretical and conceptual understanding of care, drawing on Nias and Noddings, explored in Chapter 2 to posit Tronto's (1993) political ethic of care as necessary to interpreting the sensuous experience of everyday work during the inspection period. This involves consideration of the range of contexts in which care is experienced, including how teachers care for work, their families, how they are cared for and the nature of the relationships within the school.

The purpose is to explore and reveal the organising power at the disjuncture, the lines of fault (Smith, 2005), between the actualities of teachers' everyday experience of work as it is organised by powerful structured and structuring relations. This illuminates further political and personal and professional moral concerns. The focus is in the 'complex web of relations that reach beyond and coordinate what [they] are doing in relationship' (Smith, 2005, pp. 41-42) and analysis moves beyond individual motivations to reveal the organisation of teachers' work through an institutional manipulation of emotional labour. The teachers do care about standards and meeting the expectations of Ofsted, they also care about the whole child, each other, their place within the system and how the system objectifies them through the embodiment of work and her emotions into capital (Colley, 2011). 
In drawing on the work of Nias and Noddings, the chapter provides evidence of a duality in understanding 'need' and 'care' based on social/emotional aspects or performative requirements. However, I again emphasise the evidence that teachers' work is mediated through texts (including their own talk), which they take up in achieving balance in the process of care. To ignore the political ethic of care is to foreground a rational morality first boundary in which what is valued are essentialist, parochial practices through which teachers meet targets and the needs of the elite. However, the wider aspects of their consciousness as people cannot be ignored and theirs is a constant struggle to balance the demands foregrounded through ideological and political abstraction and their personal and professional moral boundary.

\subsubsection{Chapter 6: Silencing Care: Achieving Fidelity to Regulatory Demands}

\subsubsection{Lyn's Poem Reveals that Care Is Silenced in Achieving Fidelity to Regulatory Demands}

While the focus of the book is on the local experience at Crosstown School, that is, particular teachers, acting in a certain site at a particular time, the concern is not simply local. The local is both particular and plural (Tronto, 1993). The local is the site where wider relations of ruling are taken up, mediated and organised through locally situated social relations but this is happening in multiple sides of comparison (Ng \& Mirchandani, 2008; Smith, 2005). The boss texts, the policies and guidance, that are taken up by teachers in local sites are designed, written and ideologically constructed away from the schools that are the local sites of teachers' daily work.

In this context, texts mediate understanding that some people are cared for, some are caregivers and others can absent themselves from caring responsibility in local sites altogether. Therefore, any discussion of teachers' work and everyday experiences of care need to account for inequality in relations. This is demonstrated in the diminution of teachers understanding of themselves as care receivers and such inequality renders the notions of attentiveness, responsibility or privileged irresponsibility problematic and a moral concern (Tronto, 1993).

The actuality of the everyday is initiated by teachers within 'a local moment of use' (DeVault, 2006, p. 44) and what is used includes Ofsted inspector's reports. In reading and taking up the report the teachers engage in a dialogical struggle for what has not yet been spoken to find expression, in the moment of its utterance, though a language embedded in relations of ruling (Smith, 1997, 2005). This chapter, therefore, focuses on the disjunctures arising in the teachers' talk and the organisation of practices of care through the materiality of inspectors' reports. It explicates different forms of consciousness in the relation between caregiving and care receiving and describes how externally mediated relations of ruling shape teachers' everyday work with children and each other. 


\subsubsection{Chapter 7: Teachers' Experience and Understanding of Care}

\subsubsection{Jennie's Poem Reveals a Concern About Trust}

This concluding chapter again emphasises the trans-local, extra-local and situated connections and coordination of work during a time of enhanced scrutiny and accountability which give rise to disjunctures in the teachers' wider experience and understanding of care. Analysis reveals an understanding of care as political and moral and involving more than the discourses of intimate relationships and behaviour role modelling promoted in policy and guidance as necessary to good pupil outcomes.

Discussion reveals the hierarchy of textual mediation of teachers' work and explicates how teachers come to care through political, moral, and personal and professional moral boundaries. This leads to concerns over pedagogical principles, workload, stress and a wider consciousness of the teachers' self. When behaviour and practice are regarded as risky to pupils, the school, colleagues and self, the recourse, through talk, is to take up the institutional discourse of quality mediated through regulation. A key finding is that teachers' wider care needs are silenced.

Tronto in developing her approach also acknowledged that women's work has been 'historically gendered, raced and classed' (1993, p. 112). That is, it is women who are predominately socialised to adopt caring responsibilities within the family, and this form of social organisation is also a matter of an economic relationship in which the most powerful and wealthy are able to pass responsibility for their own caring work to others. An aspect of this, and one interpretation of the teachers' experience, is to foreground a 'good' practitioner in terms of outcomes achieved through her skills, knowledge and values (of a particular kind). The prevailing narrative of 'risk' gives rise to questions of trustworthiness when teachers are seen as a threat to desired outcomes (O'Neill, 2013). However, the reduction of trust to mean meeting the needs of the elite through a solely cognitive process does not fully account for the teachers' consciousness of the struggle between ruling relations of power, politics, morals and values. In Walker's (1998) and Tronto's (1993) terms women's standpoint is not simply reducible to a person's cognitive disposition but an achievement of critical consciousness, political struggle and reflexivity. 